\title{
OS DISCURSOS DA COMUNIDADE DISCIPLINAR DE ENSINO DE BIOLOGIA: CIRCULAÇÃO EM MÚLTIPLOS CONTEXTOS
}

\author{
Biology Education Discourses: \\ circulation in multiple contexts
}

\author{
Flávia Busnardo ${ }^{1}$ \\ Alice Casimiro Lopes ${ }^{2}$
}

Resumo: Apresentam-se os principais discursos que circulam no âmbito das discussões da comunidade de Ensino de Biologia e busca-se relacioná-los com a produção de políticas curriculares, a partir da abordagem do ciclo de políticas de Stephen Ball e do entendimento de comunidade disciplinar e disciplina escolar de Ivor Goodson. Para tal, foram analisados trabalhos relacionados à temática currículo apresentados nos principais eventos da área de Ensino de Biologia. Por intermédio da análise dessas produções, em sua maioria de autoria de professores da Educação Básica, concluímos que muitos dos discursos apresentados nos documentos oficiais das políticas curriculares incluem sentidos do contexto da prática, assim como discursos dos documentos são incorporados à prática dos professores. Dessa forma, evidenciamos como as políticas curriculares são produções de múltiplos contextos, fruto das circularidade de discursos. Igualmente, buscamos compreender o processo de hegemonização (Ernesto Laclau) de sentidos nas políticas curriculares.

Palavras-chave: Políticas curriculares. Comunidade disciplinar. Ensino de Biologia. Currículo integrado.

Abstract: This research brings to light the main discourses that circulate in the Biology Education field. The aim is to relate them to the production of curriculum policy, based on the 'policy cycle approach' formulated by Stephen Ball and the understanding of the disciplinary community and the school disciplines grounded on the works of Ivor Goodson. The investigation was based on the analyses of communication presented in the main national Biology Education events. Trough these papers review, which in the most part were written by teachers of Basic Education, we conclude that most of the discourses presented in the official documents of curriculum policy include the practice context; also, discourses from the documents are incorporated to teachers' practice. The study recognized how the curriculum policies are a product of several contexts, result of discourses circularity. The research also aimed to understand the hegemonization process (Ernesto Laclau) in the curriculum policies.

Keywords: Curriculum policy. Disciplinary community. Biology Education. Integrated curriculum.

\footnotetext{
${ }^{1}$ Licenciatura em Ciências Biológicas. Mestranda em Educação, Universidade do Estado do Rio de Janeiro (UERJ). Rio de Janeiro, RJ, Brasil. <flavia.busnardo@gmail.com>

${ }^{2}$ Licenciatura em Química. Doutora em Educação. Docente, Faculdade de Educação, UERJ. Rio de Janeiro, RJ, Brasil. <alice@curriculo-uerj.pro.br>
}

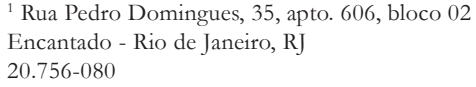




\section{Introdução}

Temos trabalhado em nossas pesquisas buscando desenvolver a interpretação das políticas de currículo como produções não-verticalizadas e descentradas, resultados de uma circularidade de textos e discursos, nos quais se destaca a atuação das comunidades disciplinares. Tais comunidades produzem sentidos para estas políticas e recontextualizam seus discursos, contribuindo para a produção de outros discursos que, por sua vez, são incorporados, de forma hibridizada, pelos textos das propostas curriculares. Salientamos, ainda, quanto os textos são abertos a múltiplas leituras que produzem currículo nas escolas, sendo necessário considerar como não-fixos os sentidos que são atribuídos ao que entendemos como currículo. É a busca de fixação parcial desses sentidos que caracteriza as lutas hegemônicas nas políticas de currículo (LACLAU, 1996).

Tal interpretação ancora-se na abordagem do ciclo contínuo das políticas educacionais de Stephen Ball (1994) e Bowe, Ball e Gold (1992), mas busca sua ampliação para o campo das políticas de currículo. Partimos da argumentação geral de que as propostas oficiais se apropriam de discursos já circulantes na prática educacional e de que, assim, sentidos das práticas estão hibridizados a essas propostas ${ }^{3}$. Dessa forma, é constituída a hegemonização de uma dada orientação curricular pela circulação de significantes nos quais se articulam múltiplos sentidos capazes de garantir o apoio às propostas.

Com base nessa compreensão mais ampla, analisamos, neste artigo, a circulação de discursos curriculares na comunidade disciplinar de Ensino de Biologia, entendendo que contribuem na produção de políticas de currículo, na medida em que legitimam determinados sentidos curriculares em detrimento de outros e expressam embates entre determinados discursos. Destacamos a (re)apropriação dos Parâmetros Curriculares Nacionais para o Ensino Médio (PCNem) $)^{4}$ pela comunidade disciplinar de Ensino de Biologia e seu trabalho com o currículo integrado articulado a uma abordagem sobre os saberes não-acadêmicos. Entendemos como saberes não-acadêmicos aqueles situados fora dos limites das disciplinas de enfoque mais acadêmico e que visam tanto uma maior integração curricular como uma relação mais ampla com o cotidiano. Nessa compreensão ampla, esses saberes são denominados populares, cotidianos ou, mesmo, saberes prévios dos alunos ou contextualizados. Tais diferentes tendências tendem a ser articuladas nas atuais políticas de currículo, mesmo guardando marcas de tradições curriculares distintas 5 .

\footnotetext{
${ }^{3}$ Análise correlata, considerando a comunidade disciplinar de Ensino de Química, pode ser conhecida em Lopes (2005b).

${ }^{4}$ À época desta investigação, as Orientações Curriculares Nacionais para o Ensino Médio (OCNem) ainda não tinham maior divulgação, daí a opção pela análise dos PCNem.

${ }^{5}$ Tais marcas podem ser mais ou menos políticas, psicológicas, marxistas ou freireanas, com diferentes níveis de deslizamentos entre as mesmas, nem sempre permitindo uma categorização fixa. Para a análise de como alguns desses deslizamentos se expressam nos PCNem, ver Lopes (2002).
} 
Reunimos, como material empírico dessa análise, os anais dos principais eventos de Ensino de Biologia no período de 1988 a 2006: Encontro Perspectivas em Ensino de Biologia (EPEB), de 1988 a 2006; Encontro Regional de Ensino de Biologia (EREBIO), de 2001 e 2003, e I Encontro Nacional de Ensino de Biologia (ENEBIO) realizado em conjunto com o III EREBIO em 2005.

Esses eventos destinam-se à divulgação de uma grande variedade de trabalhos que vêm sendo produzidos no âmbito da comunidade de Ensino de Biologia e se constituem em um efetivo canal de socialização do que é produzido, nas mais diversas linhas de pesquisa, nesse campo. A expressividade desses eventos é ainda maior se considerarmos o fato de essa comunidade disciplinar não possuir, até o momento, uma revista científica de circulação nacional, tornando a produção da área disseminada em revistas de Educação e/ou de Ensino de Ciências. Optamos, assim, pela análise dos eventos ao invés da produção em periódicos, por existir maior variedade de trabalhos nos anais, muitos dos quais, posteriormente, são publicados em periódicos e mesmo em livros. Em síntese, a produção veiculada nesses eventos é entendida, por nós, como expressiva dos discursos circulantes no campo de Ensino de Biologia, discursos esses compreendidos como produtores de sentidos para as políticas de currículo.

A organização desses eventos pela comunidade disciplinar de Ensino de Biologia se desenvolve em torno da Associação Brasileira de Ensino de Biologia (SBEnBio). Essa associação, criada em 1997, dedica-se a promover o diálogo entre professores, pesquisadores e estudantes do Ensino Superior e da Educação Básica sobre as questões que permeiam o campo de Ensino de Biologia, buscando incentivar o desenvolvimento do ensino e da pesquisa neste campo. Quando comparada às Divisões de Ensino das sociedades de outros campos do ensino de Ciências, como a Química e a Física, a SBEnBio é uma sociedade muito nova. Em parte, essa formação mais tardia deve-se ao fato de a Biologia não ter uma sociedade científica única, estando organizada em múltiplas sociedades, dado seu próprio caráter de uma disciplina dividida em subdisciplinas: Botânica, Ecologia, Zoologia, Genética, dentre outras. Igualmente, é possível identificar que os Programas de Pós-graduação em Ensino de Ciências ou as linhas de pesquisa em Ensino de Ciências nos Programas de Educação não contam com especialistas em Ensino de Biologia na mesma proporção que nos campos de Ensino de Física e de Química.

Tais características, no entanto, não impediram a paulatina formação de pesquisadores no campo de Ensino de Biologia, notadamente com um diálogo mais amplo com o campo educacional, na medida em que muitos desses pesquisadores se formaram em Programas de Pós-graduação em Educação, sob orientação de pesquisadores desse campo. As trajetórias desses pesquisadores - aspecto merecedor de estudos mais específicos - acabam por conferir à comunidade de Ensino de Biologia características peculiares frente às outras comunidades de ensino de Ciências, no que concerne ao diálogo com o campo educacional e às temáticas privilegiadas.

Destacamos, também, que, de forma mais significativa que as demais comunidades de ensino de Ciências, a comunidade de Ensino de Biologia atua no Ensino Fundamental e no Ensino Médio, com professores de Ciências e de Biologia, produzindo discursos para as políticas na área. Assim, as divisões entre discursos curriculares para o Ensino Fundamental e para o Ensino Médio são menos distintas que em outras áreas.

Nos eventos mencionados, buscamos analisar os trabalhos que se remetem às seguintes temáticas: abordagem dos parâmetros curriculares nacionais (PCN) e demais propostas 
curriculares para os diferentes níveis de ensino, seja por intermédio da apresentação e/ou análise de projetos desenvolvidos utilizando os princípios curriculares dos documentos, seja pelo processo de buscar legitimação de determinada investigação e/ou relato de experiência por meio das argumentações dos PCN, seja ainda pela comparação de experiências já em execução - livros didáticos, propostas curriculares - em relação ao que é sugerido pelo documento. Igualmente, foram incluídos trabalhos que apresentam alguma análise crítica dos PCN e/ou da política propriamente dita, trabalhos que abordam currículo integrado nas suas mais diversas modalidades (interdisciplinaridade, currículo por projetos, por temas transversais, por temas geradores e currículo por competências) e aqueles que se referem aos saberes nãoacadêmicos, seja por meio da abordagem dos saberes populares, cotidianos, saberes prévios ou, simplesmente, contextualização. Na seleção dos trabalhos, não nos preocupamos em distinguir quando os autores eram pesquisadores ou professores da Educação Básica, ambos ativos participantes desses eventos. Tampouco foi objeto de nossa investigação a filiação institucional dos autores. Isso porque procuramos entender os discursos que circulam na comunidade disciplinar de Ensino de Biologia, e não em dadas instituições específicas. Igualmente, porque muitos trabalhos são frutos de associações entre pesquisadores e professores, dada à tendência da área de ter uma inserção acentuada na Educação Básica, seja por intermédio de projetos de pesquisa e extensão específicos, seja por meio das atividades das disciplinas de Prática de Ensino no nível superior.

Os 228 trabalhos selecionados foram submetidos a uma análise qualitativa que buscou entender os principais sentidos priorizados nessas investigações. Nossa opção por não apresentar dados quantitativos de cada uma das tendências investigadas deve-se ao fato de existir entrelaçamento de sentidos que não permite categorização exclusiva de um trabalho em dada tendência.

Para análise dessa produção, organizamos este artigo de forma a apresentar, na próxima seção, uma síntese das discussões teóricas que embasam os argumentos que defendemos na pesquisa, com especial destaque para as abordagens de ciclo de políticas e de discurso. Em seguida, buscamos apresentar nossas concepções de disciplina escolar e de comunidade disciplinar, assim como apresentar os principais resultados encontrados na nossa investigação dos trabalhos dos eventos. Por fim, apresentamos nossas conclusões.

\section{Os discursos nas políticas}

A abordagem do ciclo contínuo de políticas de Stephen Ball (1994), expressa particularmente nos contextos de influência, da produção de textos e da prática, já foi apresentada em diferentes trabalhos (DIAS, 2008; LOPES, 2008, 2005b; ABREU e LOPES, 2006; DIAS e ABREU, 2006; DIAS e LOPES, 2006; MAINARDES, 2006). Todavia, consideramos importante esclarecer ainda que o termo contexto, neste ciclo, não se refere a um território definido, fixo. Esse é um modelo heurístico, no qual os contextos são simbólicos e devem ser determinados no escopo da política focalizada. Pode haver casos em que a análise da política nos mostre que, no próprio contexto micro - a escola -, seja possível delinear três contextos (influência, produção de textos e prática), em virtude do foco de investigação escolhido.

$\mathrm{Na}$ investigação em pauta, podemos destacar a importância da atuação da comunidade disciplinar de Ensino de Biologia nos três contextos do ciclo de políticas, com ênfase maior 
nos contextos da produção de texto e da prática. Essa comunidade disciplinar guarda uma particularidade em relação às demais comunidades disciplinares da área de ensino de Ciências, como as comunidades de ensino de Química e Física, na medida em que a maioria dos responsáveis pela elaboração de documentos curriculares oficiais, como os PCNem, são professores da Educação Básica ${ }^{6}$. Já nas áreas de Química e Física, os responsáveis pela elaboração dos documentos foram, em sua maioria, pesquisadores e especialistas da área.

O fato de professores da Educação Básica serem indicados para elaborar os documentos da área de Biologia possibilita que fique ainda mais evidenciado como discursos já usuais no contexto da prática são contemplados na escrita dos documentos de caráter oficial. Essa característica é corroborada pela análise dos trabalhos dos eventos investigados, como abordaremos mais a frente neste artigo. Entretanto, assim como discursos da prática tomam corpo nas propostas, as propostas influenciam discursos nas práticas. Discursos apresentados nos textos da política são apropriados e recontextualizados pelos professores no âmbito de suas práticas, por intermédio das leituras que realizam desses textos. Essas ressignificações de discursos são, reforçando o movimento de circularidade que defendemos, apropriadas no contexto de produção de textos das políticas, contribuindo para a produção de novas políticas. Como afirma Ball (2001), as políticas são produtos de acordos, elaboradas por meio de complexos processos de influência, produção e disseminação de textos, mas estão sujeitas à recriação no contexto da prática.

Tal atuação da comunidade disciplinar de Ensino de Biologia contribui para reforçar a defesa de que não faz sentido a distinção entre proposta e prática curriculares. Apesar de reconhecermos que, de fato, existem documentos oficiais norteadores da reforma e que a assinatura oficial contribui para limitar possíveis leituras do texto, as classificações entre proposta e prática tornam-se mais indistintas, na medida em que sentidos são intercambiados mutuamente na produção curricular. Procuramos, portanto, pensar a prática como parte da política, visto que sentidos da prática estão representados nos textos orientadores das políticas de forma bastante imbricada e circulam em múltiplos contextos da política. Fica evidenciada, assim, a constante produção de políticas no contexto da prática.

Outra importante contribuição de Ball (1994) que merece ser destacada é a concepção da política curricular como discurso e como texto. Como texto, considera-se a política como uma representação expressa por meio da linguagem e, assim, pode ser interpretada. Como discurso, a política curricular não se limita à linguagem. Ela não pode ser compreendida sem levar em consideração as relações materiais que a constituíram. A política curricular analisada como um discurso, portanto, é entendida como uma prática discursiva, prática essa que constitui aquilo do que se fala.

Nessa perspectiva, buscamos nos afastar de enfoques que compreendem o discurso apenas como um conjunto de signos, meros transmissores de significados, alguns visíveis, explícitos, e outros intencionalmente ocultos. Para Foucault, não há nada por trás dos discursos; o discurso é composto por enunciados e é fruto de relações históricas, políticas e práticas

${ }^{6}$ Essa marca no processo de elaboração de textos curriculares oficiais foi modificada no caso das OCNem. 
que são postas em funcionamento (FISHER, 2001). Articulada à compreensão de discurso apresentada acima ${ }^{7}$, trabalhamos com a compreensão de discurso proposta por Laclau (2005). Para o autor, o discurso não se reduz à linguagem, a um conjunto de palavras, pois engloba a materialidade das instituições e as práticas econômicas, sociais e políticas. Nessa perspectiva, abrange tanto o que é linguístico quanto o que é extralinguístico. Laclau destaca também o fato de o discurso ser contingente. Tal contingência possui relação com a imensa possibilidade de produção de sentidos que perpassam um sistema discursivo (MENDONÇA, 2006).

No caso das políticas curriculares, analisá-las como discurso significa tentar escapar do pressuposto de que devemos ler os documentos com a intenção de interpretar o que está por trás deles. Como discursos, eles são produções históricas, políticas e constituidoras de práticas que formam os objetos das quais falam.

Na concepção de Foucault, o discurso é uma prática social produzida em relações de saber e poder. Assim, o discurso é constitutivo da realidade e produz inúmeros saberes, assim como o poder. Segundo Foucault: "o discurso não é simplesmente aquilo que traduz as lutas ou os sistemas de dominação, mas aquilo por que, pelo que se luta, o poder do qual nos queremos apoderar" (FOUCAULT, 1996, p. 10).

Os efeitos das políticas, mais especificamente das políticas curriculares, como discursos são contextuais e contingentes. Metodologicamente, tentamos compreender uma política nas relações que a produziram, de forma associada às regras que nortearam sua prática discursiva. Como discursos, as definições políticas, ao formarem os objetos dos quais falam, se associam ao que pode ser dito, a quem pode dizer, quando e com que autoridade (BALL, 1994). As políticas estão assim engendradas em relações de poder, são resultados das disputas e negociações travadas no âmbito governamental e fora dele.

Ainda segundo Foucault (1996), há diversos procedimentos que se destinam a controlar e delimitar o discurso. Esses procedimentos de regulação se exercem do exterior e do interior do discurso. Aqueles que se exercem do exterior funcionam como sistemas de exclusão, colocando em jogo o poder e o desejo inerentes ao discurso. No caso dos procedimentos internos, são eles mesmos quem regulam o discurso, isto é, procedimentos que classificam, ordenam e distribuem. Dentre esses procedimentos de regulação ganham destaque as disciplinas e, dentre elas, em especial as disciplinas escolares.

\section{Disciplina escolar e comunidade disciplinar}

Foucault (1996) apresenta a ideia de disciplina como uma das formas de regulação da produção do discurso e a define como: "[...] um domínio de objetos, um conjunto de métodos, um corpus de proposições consideradas verdadeiras, um jogo de regras e de definições, de técni-

\footnotetext{
${ }^{7}$ Com Laclau, procuramos nos afastar da distinção estabelecida por Foucault entre práticas discursivas e não-discursivas, por considerar que, dessa forma, ainda se mantém, em algum nível, uma determinação extradiscursiva.
} 
cas e de instrumentos [...]" (p. 30). Assim, a disciplina se apresenta como uma forma de controlar a produção do discurso. Nas palavras de Foucault (1996, p. 36): "[...] ela lhe fixa os limites pelo jogo de uma identidade que tem a forma de reatualização permanente de regras. [...]".

Cabe ressaltar que nosso entendimento sobre as disciplinas escolares não as compreende apenas com base em sua dimensão epistemológica, mas sim como construções políticas e sociais em constante mudança (LOPES, 2008; LOPES e MACEDO, 2002). Aproximando a concepção de Foucault de nossa compreensão de disciplina escolar, podemos inferir que as disciplinas escolares atuam "regulando" discursos, aquilo que pode ser dito e compreendido, seguindo padrões do que tradicionalmente foi selecionado no currículo como importante de ser reproduzido. Além disso, de acordo com as teorizações de Foucault, é possível perceber um entrelaçamento entre disciplina e discurso, na medida em que os discursos são produções históricas, políticas e constituidoras de práticas. Os discursos são práticas sociais, enquanto as disciplinas são frutos de processos sociais. Percebemos, assim, um forte imbricamento: o discurso, como prática social, constitui a disciplina, que é fruto de um processo social. Ao mesmo tempo, a disciplina exerce um forte controle sobre o discurso que, na verdade, é quem a constitui.

A disciplina escolar, como espaço de legitimação e produção de saberes do currículo, é cenário do estabelecimento de relações entre saber e poder. Segundo Goodson e Dowbiggin (1993), além de a disciplinaridade servir como mecanismo regulador da transmissão de conhecimentos, também serve ao Estado e aos grupos profissionais comprometidos com o ensino. Foucault fala de um poder-saber em relação às disciplinas que remetem a relações de poder perpassadas pelo saber e, assim, constituem formas discursivas de dominação.

Assim, como fruto de um processo social, a disciplina escolar envolve atores sociais na disputa por recursos, status e territórios (GOODSON, 1997). Esses atores sociais são professores da Educação Básica, pesquisadores e especialistas de suas áreas de ensino específicas, ou seja, os profissionais comprometidos com o ensino. Muitos desses professores não restringem sua atuação ao contexto da prática; eles se movimentam entre os contextos, na medida em que atuam em grupos de pesquisa em ensino nas suas áreas específicas e participam de eventos e atividades da área.

Esses atores sociais em suas áreas de ensino específicas constituem o que conhecemos como comunidade disciplinar. No âmbito de uma comunidade disciplinar surgem embates, divergências e, assim, os acordos estabelecidos são frutos de negociação entre os pares. Segundo Goodson (1997), a comunidade disciplinar não deve ser vista como um grupo homogêneo onde seus atores sociais partilham os mesmos valores e interesses. A comunidade disciplinar constitui-se em um movimento social que inclui diferentes grupos de indivíduos que se organizam em torno de disciplinas escolares e que se desenvolvem, frequentemente, nos períodos em que se intensifica o conflito sobre currículo e, consequentemente, o que está de certa forma ligado a ele, como recursos e formação.

Os textos da comunidade disciplinar de Ensino de Biologia expressam, em nosso entendimento, esses embates, divergências e acordos que contribuem na produção de políticas de currículo. São, assim, expressões discursivas dessa comunidade, pelas quais as políticas de currículo também são produzidas. 


\section{Os discursos circulantes na comunidade disciplinar}

Os trabalhos analisados transitam pelos mais variados temas e vão desde o relato de utilização de um determinado jogo didático em sala de aula até pesquisas que se debruçam sobre a análise de documentos oficiais. A quantidade de trabalhos que relatam experiências em sala de aula é muito mais expressiva do que aqueles que descrevem pesquisas acadêmicas, denotando quanto o campo permanece aberto à proposição curricular e metodológica.

A riqueza e diversidade destes trabalhos permitem identificar as principais tendências que circulam no âmbito da comunidade disciplinar de Ensino de Biologia e, dessa forma, compreender os principais discursos relacionados às políticas de currículo. Dentre esses discursos podemos destacar as propostas de currículo integrado e de valorização dos saberes não-acadêmicos. Esses discursos se inter-relacionam, na medida em que é possível perceber que a valorização dos saberes não-acadêmicos é fortemente associada à insatisfação dessa comunidade com a organização curricular tradicional. Em muitos trabalhos percebemos o questionamento à organização disciplinar do currículo e, assim, os professores parecem buscar alternativas a essa organização por intermédio da relação dos conteúdos biológicos com conteúdos não-acadêmicos, visando tornar os conteúdos de Ciências e de Biologia mais atraentes, motivadores e geradores de uma aprendizagem efetiva e permanente, fugindo do contexto apenas memorístico, considerado característico da organização dos conteúdos apresentada no currículo tradicional. Esse questionamento à organização tradicional da disciplina tem relação, por sua vez, com o questionamento do currículo acadêmico, visto que o currículo disciplinar é fortemente marcado pela fragmentação típica do currículo acadêmico.

Como esses discursos são produzidos em um diálogo com os PCN, seja do nível fundamental ou do nível médio, procuramos destacar também a relação que a comunidade estabelece com esses documentos.

Muitos dos discursos preconizados pelos PCNem, como, por exemplo, os discursos sobre interdisciplinaridade e contextualização, já circulavam, de alguma forma e com variados enfoques, nas discussões da comunidade de Ensino de Biologia. Nesse caso, é possível identificar dois movimentos: por um lado, os documentos oficiais anunciam princípios e propostas como inovadores quando, muitas vezes, estão se apropriando de discursos tradicionais no campo educacional. Por outro lado, os participantes da comunidade disciplinar, professores e pesquisadores, passam a citar os documentos em suas pesquisas na busca por legitimar práticas que valorizam. Essas duas tendências estão, de fato, bastante inter-relacionadas, mutuamente se corroborando.

Nossa análise nos permite considerar que são praticamente ausentes os trabalhos que abordam as recentes propostas curriculares nacionais em uma perspectiva crítica. Essa característica parece se mostrar peculiar ao Ensino de Biologia, visto que nas demais áreas relacionadas ao Ensino de Ciências, como a Física e a Química, há um grande número de trabalhos que se dedicam a analisar os documentos oficiais (ABREU e LOPES, 2008; ABREU e LOPES, 2006; SILVA, 2006). Ao mesmo tempo em que essa peculiaridade pode indicar uma postura menos crítica por parte da comunidade de Ensino de Biologia, em relação a essas propostas, também pode expressar uma menor penetração desses documentos. Ainda assim, é possível identificar, em trabalhos com propostas de conteúdos e metodologias, a constante referência aos PCN como fonte de corroboração das atividades apresentadas. Na análise dos 
anais do VII EPEB, evento que ocorreu no ano de 2000, foi possível identificar trabalhos que já mencionam, em suas referências bibliográficas, os Parâmetros Curriculares Nacionais, documentos publicados oficialmente nos anos de 1997 (documentos para o Ensino Fundamental) e 1999 (documentos para o Ensino Médio). No ano de 2000, portanto, esses textos já estavam no centro de uma intensa discussão mediada pelos professores da Educação Básica no escopo de suas práticas ${ }^{8}$.

O discurso de valorização do currículo integrado é significativamente disseminado pela e na comunidade disciplinar de Ensino de Biologia, particularmente com relação à interdisciplinaridade ${ }^{9}$. A investigação dos trabalhos revela que essa comunidade buscou articulação com esse princípio antes mesmo da elaboração e implementação dos Parâmetros Curriculares Nacionais para o Ensino Médio (PCNem), documento que valoriza esse princípio.

Algumas dessas propostas curriculares, de forma geral, não circulam de forma a produzir novos sentidos e significados sobre interdisciplinaridade e demais modalidades de currículo integrado, mas contribuem para validar atividades usuais no contexto da prática. Tais atividades passam a ter, em uma proposta com aval oficial, a possibilidade de serem amparadas, visto que muitos professores veem o documento como algo a ser seguido, mesmo esse não possuindo caráter obrigatório do ponto de vista legal.

A realização desses projetos seguiu os princípios do Ensino de Biologia: relevância do contexto social no ensino; processo de produção de conhecimento; enfoque ecológico; evolução como linha unificadora dos conteúdos biológicos, sugeridos na "Proposta Curricular para o Ensino de Biologia para o $2^{\circ}$ grau" - Secretaria de Estado da Educação - SP e CENP e, permitiu associar diversas áreas de estudo em Biologia entre si e com outros componentes curriculares (Português, Matemática, História, Geografia, OSPB). (JANONE, 1991, p. 173-174)

A abordagem de um currículo integrado por intermédio da modalidade interdisciplinar também se faz presente em trabalhos que defendem a integração entre os conteúdos mediada por questões atuais, cotidianas, contextualizadas, ou seja, mais próximas da realidade do aluno e distantes dos saberes acadêmicos. A contextualização dos conceitos ou sua relação com o cotidiano é interpretada como um processo intrinsecamente interdisciplinar, dada a complexidade do mundo em que vivemos ${ }^{10}$.

Esse avanço do conhecimento exigirá também, que cada vez mais o currículo de Biologia privilegie noções mais fundamentais e integradoras desse conhecimento. Todos esses aspectos reafirmam a necessida-

\footnotetext{
${ }^{8}$ Para mais detalhes, ver Busnardo e Lopes, 2007b.

${ }^{9}$ Para mais detalhes, ver Busnardo e Lopes, 2007c.

${ }^{10}$ Para mais detalhes, ver Busnardo e Lopes, 2007a.
} 
de de se viabilizar a integração das várias sub-áreas da Biologia. [...] Uma mudança radical seria romper com o ensino através de disciplinas e trabalhar com temas integradores. [...] As disciplinas seriam agrupadas e planejadas através de blocos integradores, buscando-se as idéias/ conceitos comuns entre elas. [...] Desenvolver atividades (sob a forma de projeto) interdisciplinares de caráter intra ou extracurriculares que permitissem uma maior integração do aluno com a sua comunidade. (BORGES, 1994, p. 105-106)

Em favor da especificidade da disciplina Biologia, contudo, é argumentado que a interdisciplinaridade não compromete um território suposto como consolidado.

Do entrecruzamento de informação das outras áreas de conhecimento e de visões diferentes, "desconstruiu-se" uma biologia clássica, arrumada e funcionando segundo normas preestabelecidas, para dar início a construção de uma Biologia mais real e comprometida com as grandes questões da atualidade. Uma Biologia que em vez de perder sua identidade, fortaleceu-se com os conhecimentos e leituras das demais disciplinas. (CADEI, 2000. p. 494-497)

O enfoque nos saberes não-acadêmicos, por vezes traduzidos pela ideia de contextualização, é acentuado em trabalhos sobre currículo integrado que apresentam como tema principal a Educação Ambiental. Este tema é considerado interdisciplinar por excelência, pois o meio ambiente é entendido como uno e integrado e, portanto, como devendo ser investigado por teorias que possibilitem a integração entre as disciplinas. Defende-se, ainda, a integração entre teoria e prática no estudo das questões ambientais, com o argumento de que se trata de um tema de grande complexidade. Por sua vez, no campo específico da Educação Ambiental, há um enfoque extremamente crítico da organização disciplinar, capaz, inclusive, de restringir o apoio a propostas de inclusão desse tema como disciplina escolar (LIMA e VASCONCELOS, 2007).

No entanto, dada a complexidade da temática ambientalista, o trabalho interdisciplinar é, na opinião de vários autores, uma das condições para que essa tarefa possa ser realizada. [...] objetivos [...] investigar o interesse e o envolvimento do corpo docente dos alunos em propostas de trabalho interdisciplinares e as condições mínimas das escolas da rede pública para o desenvolvimento de atividade dessa natureza. (SOUZA, CARVALHO e ALMEIDA, 1994, p. 131-132)

A Educação Ambiental se caracteriza por ser interdisciplinar, contínua e abrangente. Trata-se de uma prática aglutinadora alicerçada na teoria dialética prática-teoria-prática, o que permite o inter-relacionamento do conhecimento das diferentes áreas do saber. [...] Para exercitar a interdisciplinaridade, a estratégia pode ser o "tema gerador" que, segundo 
Freire (1979), possibilita o desdobramento em outros temas e provoca novas tarefas a serem cumpridas. (FERREIRA, 1994, p. 87-89)

A utilização do conteúdo de forma mais próxima do cotidiano do aluno está relacionada, de modo geral, à ideia de motivação como facilitadora do processo de aprendizagem e de alguma possibilidade de intervenção no mundo em que vivemos.

[...] procurou-se desenvolver novos materiais capazes de motivar as crianças de menor idade para os temas ambientais e de saúde, os quais estivessem ao alcance de sua compreensão; que focalizassem aspectos relevantes para o seu comportamento individual face à preservação do meio ambiente e da saúde; que despertassem a sua curiosidade, estimulando a observação da realidade e sua possibilidade de intervir na mesma de forma coletiva e organizada. [...] Assim utilizado, o material cumpre uma função educativa mais ampla de integração entre diversas áreas de ensino e de estímulo à criatividade e participação. (SCHALL, 1994, p. 33-35)

A integração entre o trabalho coletivo e interdisciplinar e a análise multidimensional do ambiente talvez não resolvam todas as dificuldades inerentes ao espaço educacional, o que transcende o querer dos docentes e discentes, mas, até onde pudemos experimentar, pode facilitar a interlocução com o conhecimento, contextualizando estes espaços ao cotidiano próximo e distante dos envolvidos. (PETTIROSSI, ROSSETO e SHIMABUKURO, 2000, p. 497-502)

Esse discurso articula-se, de forma mais ampla, à defesa dos saberes não- acadêmicos, aqueles que não são incluídos como parte dos saberes disciplinares e, por esse motivo, não costumam ser valorizados. Discursos valorizadores dos saberes não-acadêmicos são frequentes ao longo da história do currículo (LOPES, 2008), mas nem sempre são valorizados por sua importância cultural e política intrínseca. Frequentemente, como parece ser o caso na comunidade de Ensino de Biologia, são compreendidos como facilitadores da aprendizagem, por se aproximarem da realidade dos alunos, auxiliando, assim, a compreensão dos saberes disciplinares, aqueles tidos como os que realmente importam para uma aprendizagem significativa do aluno. Nessa perspectiva, nem sempre a valorização desses saberes significa uma desvalorização dos saberes acadêmicos. Ao contrário, sua inserção no currículo pode ser em posição subalternizada, submetida ao que se entende como os conteúdos centrais da aprendizagem: os saberes disciplinares.

Além desse enfoque motivador da aprendizagem, nos PCNem, a ideia de contextualização vem associada à ideia de educar para o mundo produtivo, na medida em que o contexto é também compreendido como o espaço de aplicação das competências e de expressão do saber em um saber-fazer (LOPES, 2002).

Ainda assim, as abordagens que a comunidade disciplinar de Ensino de Biologia faz dos saberes não-acadêmicos viabilizam o trabalho com as modalidades de currículo integrado 
que circulam nessa comunidade. Isso porque o currículo integrado tende a ser defendido com o argumento de que permite articular os saberes disciplinares, de cunho mais acadêmico, com os saberes prévios, populares, contextuais, ou seja, os saberes não-acadêmicos. O significante interdisciplinaridade é explorado, na grande maioria dos trabalhos que discutem ou defendem propostas de currículo integrado, como sinônimo de outras modalidades de integração curricular - currículo por projetos, por temas transversais e temas geradores -, independentemente de as tradições pedagógicas que gestaram tais concepções serem bastante distintas entre si. Seus sentidos vão se articulando em uma cadeia significativa, nos termos de Laclau (2005, 1996), que torna seus elementos esvaziados de possíveis sentidos supostos como originais. Com isso, nesse processo de esvaziamento, por vezes, o significante interdisciplinaridade é interpretado como uma metodologia para ensinar conteúdos de forma integrada.

O que permite a aglutinação desses significados diversos em torno da ideia mais ampla de integração curricular é o antagonismo comum a qualquer forma de disciplinarização de cunho acadêmico. Ser ou trabalhar de forma interdisciplinar, em todos os possíveis sentidos que esse significante possa assumir, mostra-se como uma posição antagônica à organização curricular tradicional, disciplinar. Essa oposição ao currículo disciplinar tradicional, entretanto, tende a se restringir ao âmbito da busca por articular conteúdos de disciplinas diferentes, não assumindo a preocupação com uma mudança na seleção de conteúdos. Ou seja, os conteúdos ensinados não são centralmente questionados, mas sim a abordagem supostamente desarticulada que deles é feita.

Esse processo - em que acabam por prevalecer a disseminação da interdisciplinaridade e da contextualização, menos do que uma forte apropriação dos discursos dos PCNem - parece significar a hegemonia de propostas que ao longo dos anos foram se constituindo no campo pedagógico. Os atuais documentos curriculares oficiais apropriaram-se de discursos circulantes no contexto da prática e, dessa forma, além de legitimarem a própria proposta curricular oficial, potencializam a maior adesão dos professores à política. Igualmente, atuam na legitimação da própria prática, na medida em que ela passa a poder afirmar ter um apoio oficial. Só que tais propostas, ao articularem sentidos os mais diversos de integração curricular e de valorização dos saberes não-acadêmicos, vão perdendo muitos de seus sentidos, supostos como originais. Dentre eles, destacamos os sentidos políticos e de cunho emancipatório. Nos discursos circulantes nos eventos de Ensino de Biologia, esse parece ser um silêncio ainda não preenchido por novos sentidos curriculares.

\section{Conclusões}

Essa análise dos trabalhos veiculados nos principais eventos de Ensino de Biologia permite apontar algumas conclusões. Uma delas é a de que as propostas curriculares oficiais se apropriam de discursos legitimados no campo educacional, produzindo, dessa forma, sua própria legitimação. Exemplificamos esse processo por intermédio da análise da abordagem dos princípios de contextualização e de interdisciplinaridade que são temáticas centrais nos PCNem. A análise dos trabalhos permitiu identificar que conceitos relacionados à contextualização e interdisciplinaridade, mesmo que vinculados a outros significantes, são presentes nas produções da comunidade disciplinar de Ensino de Biologia antes dos PCNem. 
Tal conclusão também se mostra como evidência de que as propostas curriculares produzidas em âmbito oficial apropriam-se de discursos circulantes nas práticas de sala de aula, buscando maior legitimidade e adesão à proposta por parte dos professores. Inferimos, contudo, que o mesmo se desenvolve para outras concepções curriculares.

O discurso sobre interdisciplinaridade, principal modalidade de currículo integrado que aparece nos trabalhos, não é um discurso novo no campo, mas que vem ganhando força desde o início da década de 1990, associado às mudanças na organização social do conhecimento. É um discurso que vem associado a distintas finalidades sociais e defendido como uma forma de organização do conhecimento escolar capaz de garantir a melhoria do processo de ensino-aprendizagem e/ou o estabelecimento de relações menos assimétricas entre os saberes e os sujeitos no currículo.

Em consonância a essa abordagem do currículo integrado, podemos considerar que a grande quantidade de trabalhos relacionados aos saberes não-acadêmicos (saberes prévios, populares, cotidianos, contextualizados) é usualmente associada à insatisfação dessa comunidade disciplinar com a organização curricular tradicional. A relação dos conteúdos biológicos próprios da disciplina com os saberes não-acadêmicos aparece como alternativa ao ensino tradicional pautado na organização disciplinar. Dessa forma, busca-se, por meio de uma abordagem menos acadêmica, tornar os conteúdos biológicos mais atraentes e motivadores. Esses saberes, constituídos fora do contexto disciplinar e valorizados tanto em propostas oficiais quanto no contexto da prática, são, portanto, capazes de legitimar propostas que propõem o diálogo entre saberes disciplinares e saberes não-acadêmicos, propostas essas muitas vezes articuladas com uma abordagem integrada de disciplinas.

Um último ponto importante que destacamos nessa pesquisa é a grande circularidade de discursos no âmbito da comunidade disciplinar foco dessa investigação. Os atores sociais pesquisadores, professores do Ensino Superior e professores da Educação Básica - apropriam-se dos discursos difundidos pelos documentos oficiais, dando-lhes novos significados. Nessa circularidade, há intenso processo de ressignificação dos textos e discursos das políticas curriculares nos múltiplos contextos pelos quais elas perpassam. Essa releitura das políticas possibilita que novos discursos sejam produzidos e incorporados, o que resulta na produção de novos sentidos para as políticas curriculares.

As considerações apresentadas nos permitem reiterar a concepção de políticas com a qual trabalhamos, desenvolvida a partir dos estudos de Ball: a de que as políticas - no estudo em questão, as políticas curriculares - não devem ser consideradas como pacotes lançados pelo governo sobre as escolas. Os resultados obtidos nessa investigação corroboram a compreensão de que a produção de políticas curriculares é resultado de intensos e múltiplos processos de (re)leituras, apropriações, reinterpretações e ressignificações que envolvem todos os contextos do ciclo de produção de políticas - influência, produção de textos e prática. É possível destacar, também, que, por mais que a elaboração das políticas educacionais seja orientada, de forma geral, pelas agências internacionais de fomento, em cada contexto particular há especificidades locais, finalidades sociais específicas que direcionam a demanda dessas políticas. Isso nos permite reiterar que, mesmo na situação pretensamente homogeneizadora apresentada pelo processo de globalização, as contingências locais têm um papel de destaque na formulação das políticas. 
Burnardo, F.; Lopes, A. C.

Em um contexto discursivo, que é o caso das políticas, não há como estabelecer quais sentidos assumirão importância na representação. Os sentidos a serem assumidos são dependentes do contexto histórico e contingencial de (re)leitura das políticas. Cada local, com suas demandas específicas e contingenciais, direciona a produção de políticas de forma a "fixar" determinados sentidos que se mostram hegemônicos naquele contexto (LACLAU, 2005). Entretanto, esse processo é sempre provisório e contingente, representacional da articulação que se faz em torno das demandas equivalentes. Assim, sentidos de uma determinada política estão apenas provisoriamente fixados e são passíveis de ressignificações e recontextualizações de acordo com as demandas que se estabelecem em seu processo de produção e disseminação.

\section{Referências}

ABREU, R. G.; LOPES, A. C. A comunidade disciplinar de ensino de Química na produção de políticas de currículo. In: ROSA, M. I.; VITORINO, A. (Orgs.). Educação Química no Brasil: memórias, políticas e tendências. 1. ed. Campinas: Átomo, 2008. p. 41-62. v. 1.

. Políticas de currículo para o Ensino Médio no Rio de Janeiro. Contexto \& Educação, Ijuí, v. 21, n. 76, p. 175-200, 2006.

BALL, S. J. Diretrizes políticas globais e relações políticas locais em educação. Currículo sem Fronteiras, v. 1, n. 2, p. 99-116, 2001. Disponível em: <http:// www.curriculosemfronteiras.org:. Acesso em: 10 dez. 2008.

. Education reform: a critical and post-structural approach. Buckinghan: Open University, 1994.

BORGES, G. L. A. É possível formar professores com concepção mais integrada de Biologia? In: ENCONTRO PERSPECTIVAS EM ENSINO DE BIOLOGIA, 5., 1994, São Paulo. Anais... São Paulo: USP, 1994. p. 105-106.

BOWE, R.; BALL, S. J.; GOLD, A. Reforming education and changing schools: case studies in policy sociology. London: Routledge, 1992.

BRASIL. Ministério da Educação. Secretaria de Educação Média e Tecnológica.

Parâmetros Curriculares Nacionais para o Ensino Médio. Brasília: Ministério da Educação, Secretaria de Educação Média e Tecnológica, 1999. v. 4.

BUSNARDO, F. M. G.; LOPES, A. C. Os saberes não-acadêmicos nas propostas curriculares para o Ensino de Biologia. In: SEMINÁRIO INTERNACIONAL AS REDES DE CONHECIMENTO E A TECNOLOGIA: PRÁTICAS EDUCATIVAS, COTIDIANO E CULTURA, 4., 2007, Rio de Janeiro. Anais... Rio de Janeiro: Laboratório de Educação e Imagem, 2007a. 1 cd-rom.

.; _ـ Uma abordagem sobre políticas de currículo: apropriação dos PCN pela comunidade disciplinar de ensino de biologia. In: ENCONTRO NACIONAL DE ENSINO DE BIOLOGIA, ENEBIO, 2., 2007, Uberlândia. Anais... Uberlândia: SBEnBio, 2007b. 1 cd-rom. 
Os discursos da comunidade disciplinar ...

.; Currículo integrado no Ensino de Biologia. In: ENCONTRO

NACIONAL DE PESQUISA EM EDUCAÇÃO EM CIÊNCIAS, 6., 2007, Florianópolis.

Anais... Belo Horizonte: ABRAPEC, 2007c. 1 cd-rom.

CADEI, M. S. A prática interdisciplinar em Biologia: a reconstrução de um olhar. In:

ENCONTRO PERSPECTIVAS EM ENSINO DE BIOLOGIA, 7., 2000, São Paulo.

Anais... São Paulo: USP, 2000. p. 494-497.

DIAS, R. E. Redes políticas de formação de professores. Revista Contemporânea de

Educação, Rio de Janeiro, v. 3, n. 5, p. 34-45, 2008.

.; ABREU, R. G. Discursos do mundo do trabalho nos livros didáticos do ensino

médio. Revista Brasileira de Educação, Rio de Janeiro, v. 11, n. 32, p. 297-307, 2006.

Disponível em: <http://www.scielo.br>. Acesso em: 15 dez. 2008.

.; LÓPEZ, S. B. Conhecimento, interesse e poder na produção de políticas

curriculares. Currículo sem Fronteiras, v. 6, n. 2, p. 53-66, 2006. Disponível em: <http:// www.curriculosemfronteiras.org >. Acesso em: 15 dez. 2008.

FERREIRA, M. S. F. D. Educação ambiental através de tema gerador. In: ENCONTRO PERSPECTIVAS EM ENSINO DE BIOLOGIA, 5., 1994, São Paulo. Anais... São Paulo: USP, 1994. p. 87-89.

FISCHER, R. M. B. Foucault e a análise do discurso em educação. Cadernos de Pesquisa, São Paulo, s/v, n. 114, p. 197-223, 2001. Disponível em: <http:// www.scielo.br>. Acesso em: 2 dez. 2008.

FOUCAULT, M. A ordem do discurso: aula inaugural no Collège de France, pronunciada em 2 de dezembro de 1970. 16. ed. São Paulo: Loyola, 1996.

GOODSON, I.; DOWBIGGIN, I. Cuerpos dóciles: aspectos comunes de la historia de la psiquiatría y la enseñanza. In: BALL, S. J. (Org.). Foucault y la educación. Madrid: Morata, 1993. p. 107-131.

GOODSON, I. A. Construção social do currículo. Coletânea de textos de Goodson organizada por António Nóvoa. Lisboa: Educa, 1997.

JANONE, M. T. C. Educação ambiental através de projetos em Ecologia. In: ENCONTRO PERSPECTIVAS EM ENSINO DE BIOLOGIA, 4., 1991, São Paulo. Anais... São Paulo: USP, 1991. p. 173-174.

LACLAU, E. La razón populista. Buenos Aires: Fondo de Cultura Económica, 2005.

Emancipation(s). London: Verso, 1996.

LIMA, J. G. S.; VASCONCELLOS, M. M. N. A. Educação ambiental como disciplina escolar: explicitando a tensão entre teoria e prática. In: ENCONTRO DE PESQUISA EM EDUCAÇÃO AMBIENTAL, 4., 2007, Rio Claro. Anais... Rio Claro: Unesp/IB, 2007. v. 1. p. 1-17. 
Burnardo, F.; Lopes, A. C.

LOPES, A. C. Políticas de integração curricular. 1. ed. Rio de Janeiro: EdUerj/Faperj, 2008. v. 1.

Política de currículo: recontextualização e hibridismo. Currículo sem Fronteiras, v. 5, n. 2, p. 50-64, 2005a. Disponível em: <http://www.curriculosemfronteiras.org>. Acesso em: 15 dez. 2008.

Discursos curriculares na disciplina escolar Química. Ciência e Educação, Bauru, v. 11, n. 2, p. 263-278, 2005b.

Os Parâmetros Curriculares Nacionais para o Ensino Médio e a submissão ao mundo produtivo: o caso do conceito de contextualização. Educação e Sociedade, Campinas, v. 23, n. 80, p. 386-400, 2002. Disponível em: <http://www.scielo.br>. Acesso em: 10 dez. 2008.

LOPES, A. C.; MACEDO, E. F. A estabilidade do currículo disciplinar: o caso das Ciências. In: ___ _ _ Disciplinas e integração curricular: história e políticas. Rio de Janeiro: DP\&A, 2002. p. 73-94.

MAINARDES, J. Abordagem do ciclo de políticas: uma contribuição para a análise de políticas educacionais. Educação e Sociedade, Campinas, v. 27, n. 94, p. 47-69, 2006. Disponível em: <http://www.scielo.br>. Acesso em: 15 dez. 2008.

MENDONÇA, D. A condensação do imaginário popular oposicionista num significante vazio: as "diretas já". In: .; RODRIGUES, L. P. (Orgs.). Ernesto Laclau e Niklas

Luhmann: pós-fundacionismo, abordagem sistêmica e as organizações sociais. Porto Alegre: EdiPUCRS, 2006. p. 146-169.

PETTIROSSI, N.; ROSSETO, J. R.; SHIMABUKURO, E. K. H. Um enfoque multidimensional do ambiente. In: ENCONTRO PERSPECTIVAS EM ENSINO DE BIOLOGIA, 7., 2000, São Paulo. Anais... São Paulo: USP, 2000. p. 497-502.

SCHALL, V. T. Ciranda da saúde, do ambiente e da vida. In: ENCONTRO PERSPECTIVAS EM ENSINO DE BIOLOGIA, 5., 1994, São Paulo. Anais... São Paulo: USP, 1994. p. 33-35.

SILVA, D. B. R. A comunidade disciplinar de ensino de Física na produção de políticas de currículo. 2006. 144f. Dissertação (Mestrado em Educação) - Faculdade de Educação, Universidade do Estado do Rio de Janeiro, Rio de Janeiro, 2006.

SOUZA, A. C. C.; CARVALHO, L. M.; ALMEIDA, R. D. A temática ambiental e os trabalhos de campo: uma proposta interdisciplinar. In: ENCONTRO PERSPECTIVAS EM ENSINO DE BIOLOGIA, 5., 1994, São Paulo. Anais... São Paulo: USP, 1994. p. 131-132.

Artigo recebido em janeiro de 2010 e aceito em abril de 2010. 